\title{
How Black Are Lakisha and Jamal? Racial Perceptions from Names Used in Correspondence Audit Studies
}

\author{
S. Michael Gaddis
}

University of California, Los Angeles

Abstract: Online correspondence audit studies have emerged as the primary method to examine racial discrimination. Although audits use distinctive names to signal race, few studies scientifically examine data regarding the perception of race from names. Different names treated as black or white may be perceived in heterogeneous ways. I conduct a survey experiment that asks respondents to identify the race they associate with a series of names. I alter the first names given to each respondent and inclusion of last names. Names more commonly given by highly educated black mothers (e.g., Jalen and Nia) are less likely to be perceived as black than names given by less educated black mothers (e.g., DaShawn and Tanisha). The results suggest that a large body of social science evidence on racial discrimination operates under a misguided assumption that all black names are alike, and the findings from correspondence audits are likely sensitive to name selection.

Keywords: racial discrimination; inequality; names; audit studies; experiments

Citation: Gaddis, S. Michael. 2017. "How Black Are Lakisha and Jamal? Racial Perceptions from Names Used in Correspondence Audit Studies." Sociological Science 4: 469-489.

Received: May 18, 2017

Accepted: June 12, 2017

Published: September 6, 2017

Editor(s): Jesper Sørensen, Olav Sorenson

DOI: $10.15195 / \mathrm{v} 4 . \mathrm{a} 19$

Copyright: (C) 2017 The Author(s). This open-access article has been published under a Creative Commons Attribution License, which allows unrestricted use, distribution and reproduction, in any form, as long as the original author and source have been credited. (0)(1)
$\mathrm{M}$ ODERN social science evidence of racial discrimination stems mostly from a type of field experiment known as an audit study, which matches candidates on all characteristics except race to examine racial differences in outcomes. Originally developed in the 1960s to capture more elusive forms of racial discrimination in the post-Civil Rights era, modern audit studies have shifted from the in-person to the correspondence method, which uses names to signal the race of hypothetical subjects. With few exceptions, correspondence audits regularly find lower phone and/or email response rates for applications with black names compared to white names in both employment and housing (Gaddis 2015; Hanson et al. 2016; Hogan and Berry 2011). Researchers have continued to find evidence of racial discrimination even as correspondence audits have expanded to include a broader domain of actors, such as politicians, prospective roommates, public officials, and health care professionals (Butler and Broockman 2011; Einstein and Glick 2017; Gaddis and Ghoshal 2017; Giulietti, Tonin, and Vlassopoulos 2015; Sharma, Mitra, and Stano 2015).

Such correspondence audits enable researchers to circumvent a number of critiques of the in-person method (Heckman 1998; Heckman and Siegelman 1993), collect larger samples, and reduce research costs. However, researchers also lose the ability to more directly convey race through appearance and interaction and instead rely solely on names to signal race. The vast majority of the recent evidence on racial discrimination hinges on individuals' racial perceptions from these names.

An exhaustive search of correspondence audits (conducted by both mail and internet) that use names to signal race yields 89 studies in published or working 
paper form since 1970. The occurrence of these studies has accelerated in recent years (72 studies, or 81 percent, have been published or otherwise made available since 2010). ${ }^{1}$ Researchers across a variety of disciplines-sociology, economics, political science, psychology, and management-have published these studies in some of the top generalist journals. To fully capture the gravity of how names inform a scientific understanding of racial prejudice, discrimination, and stereotypes, we can expand the search of the scientific literature beyond correspondence audits to also include laboratory, vignette, and other experiments, which easily surpasses 250 studies since the year $2000 .^{2}$

Unfortunately, no research has systematically investigated the validity of using names to signal race. In correspondence audits, researchers seem to assume a consensus on what constitutes distinctively black and white names and that any one "black" name should yield similar results as any other "black" name. However, scientific explanations of how researchers select black and white names are woefully lacking. These explanations range from no details (10 percent) to selecting from published popular name lists (often with no racialized data) (17.5 percent), recycling Bertrand and Mullainathan's (2004) selected names (or those from Levitt and Dubner's 2005 list) (37.5 percent), using state birth record data without a pretest (17.5 percent), and using pretests to examine perceptions of names (17.5 percent). In other words, less than 1 out of every 5 studies using names to signal race has scientifically examined relevant data to see how people perceive race from the selected names. When researchers do gauge racial perceptions from names using pretests, they often have very small sample sizes and/or query only college students, and no researchers have used experimental manipulations. This is particularly troubling because name-based correspondence audits have become the leading method of providing evidence of racial discrimination.

Although the research base clearly shows that race can be signaled through names and that using names as a signal of race can successfully capture some version of racial discrimination, it is unclear whether people actually perceive the signal of race in the same way across the variety of names used in past research. At least 3 characteristics of a name may influence an individual's perception of race from that name: (1) the population racial composition of a first name, (2) the population socioeconomic status (SES) composition of a first name, and (3) the population racial composition of a last name. Although some racial discrimination research has been concerned with the second characteristic (Bertrand and Mullainathan 2004; Gaddis 2015), nearly none has paid attention to the first and third characteristics.

Studies that use names to signal race rely on the assumption that there are first names among the population that are unique to certain races. Thus, if a name, such as Jamal, more frequently belongs to a black person, the general population should recognize that name as black. Since at least the 1960s, a small percentage of black parents have chosen certain first names for their children at much higher frequencies than white parents, making these names racially distinctive (Fryer and Levitt 2004; Lieberson 2000; Lieberson and Mikelson 1995). However, the majority of black parents do not name their children using distinctive first names. For example, from 1994 to 2012 in New York state, only 15 names were used by black mothers more than 3,000 times. Most of these 15 names were commonly given by both black and 
white mothers: Anthony, Ashley, Joshua, Kayla. Only one of these 15 names was more commonly given by black rather than white mothers: Isaiah. Overall, only 18.9 percent of black children born in New York during this period have a name that is racially distinctive as black (more commonly given by black rather than white mothers).

Moreover, data from New York suggest that the most distinctively black names are not exclusively used by blacks. For example, names such as Jamal and Latoya belong to children with black mothers at rates of 80 percent and 84 percent, respectively, leaving 20 percent of Jamals and 16 percent of Latoyas as nonblack or multiracial. Other "black" names such as Keisha and Leroy have lower rates (56 percent and 61 percent, respectively). All four of these names have been used to signal black applicants in multiple correspondence audits.

Taken together, these two issues should make it clear that, at best, first names can only be imperfect proxies of race. Researchers take a shortcut by first using a specific subset of names and then taking a continuous variable of racial naming practices and turning it into a binary (i.e., white name or black name). Thus, even if data on actual population naming practices by race could perfectly predict perceptions of race from these names, we would expect that, for instance, 20 percent of the time Jamal would be perceived as nonblack. However, individual perceptions may not perfectly align with reality, as one often-overlooked small sample pretest finding from Bertrand and Mullainathan (2004) suggests. ${ }^{3}$

A second important factor determining what racial cues a first name may signal is the correlation between parental SES and names. Using birth record data from California, Fryer and Levitt (2004) find that "[b]lacker names are associated with lower-income zip codes [and] lower levels of parental education" (p. 786). Moreover, although there are fewer instances of unique naming patterns among white parents, these unique names are still correlated with SES in the New York birth record data. Because both race and SES influence parental naming practices, the racial perception from a name may be biased by the SES-based naming practices. Whereas some find that individuals' racial perceptions from names are not biased by these SES-based practices (Bertrand and Mullainathan 2004), other research suggests this may not be true in all instances (Figlio 2005; Gaddis 2015; Kirschenman and Neckerman 1991).

Finally, researchers have focused minimal attention on last name selection with regard to race. However, publicly available U.S. Census data show that only nine last names among the most frequently occurring 1,000 are majority black, with another 15 last names registering at 40 percent to 50 percent black (U.S. Census Bureau 2012). Earlier correspondence audits often mixed "black" first names with both predominantly black last names and predominantly white last names within a study (Hanson and Hawley 2011; Milkman, Akinola, and Chugh 2012), whereas more recent studies often match first and last names by race (Gaddis 2016; Hanson et al. 2016). The effect of this selection on outcomes in correspondence audits is not only unknown but heretofore unquestioned.

One additional potential wrinkle in signaling race through names remains: the characteristics of the individual receiving the signal. For instance, we might expect that blacks would be more familiar with black names generally and thus more likely to recognize a particular name as black, independent of the SES associations 
of that name. Other characteristics, such as an individual's age, gender, and SES might matter as well. Although no correspondence audits directly acknowledge this issue, the implications are clear. If whites are overrepresented in a particular audit context (e.g., real estate agents) and also less likely to receive the racial signals sent by researchers, we may underestimate true discrimination rates by using poorly performing names.

Overall, a body of research suggests that further examination of racial perceptions from names will substantially improve our understanding of existing discrepancies in racial discrimination research and help lead to future laboratory, field, and survey experiments with higher internal validity. Unfortunately, few studies have examined different perceptions of race from names and none do so in an experimental framework. The present research stands to make an important contribution to the social sciences by providing the first scientific evidence on perceptions of race from names. I proceed by conducting a survey experiment and examining a number of research questions on individual racial perceptions from names.

\section{Research Questions}

In this study, I address four primary research questions:

(1) Are individual perceptions of race from first names congruent with population-level naming practices and prior correspondence audits?

(2) Does the inclusion of different types of last names affect individual perceptions of race from first names?

(3) Do variations in population-level naming practices by race, education, and popularity affect individual perceptions of race from first names?

(4) Do respondent characteristics-particularly race, gender, age, and SES-affect individual perceptions of race from first names?

\section{Data and Methods}

\section{Using Amazon's Mechanical Turk}

To examine these research questions, I conducted a survey experiment using Amazon's Mechanical Turk (MTurk) from September 2014 through August 2015. MTurk is a crowdsourcing microtask marketplace where individuals can assign (requesters) or perform (workers) tasks (Human Intelligence Tasks, or HITs) for monetary compensation. MTurk has become popular among social scientists, particularly for conducting survey experiments in the fields of psychology, political science, sociology, and health, among others (Campbell and Gaddis forthcoming; Dowling and Miller 2016; Horne et al. 2015). Researchers have praised MTurk for its relatively low cost and quick turnaround for data and have offered cautious optimism regarding generalizability (Horton, Rand, and Zeckhauser 2011; Weinberg, Freese, and McElhattan 2014). Moreover, on a number of dimensions, MTurk represents a superior alternative to using undergraduate students, a ubiquitous sample in experimental psychology (Sears 1986). 


\section{Internal and External Validity with MTurk}

Scholars have raised two primary issues of concern about MTurk: (1) respondent demographics and representativeness, or external validity; and (2) the reliability of reporting and data quality, or internal validity. Numerous recent studies address these issues in depth. First, scholars have presented significant evidence that shows that although MTurk's pool of participants are not demographically the same as the U.S. population as a whole, the participants are also not as homogeneous as one might imagine nor radically different from the U.S. population (Berinsky, Huber, and Lenz 2012). Compared to the U.S. population, MTurk samples are composed of slightly more women and are younger and more educated but with similar income distributions to the U.S. population (Buhrmester, Kwang, and Gosling 2011; Ipeirotis 2010; Paolacci, Chandler, and Ipeirotis 2010). MTurk may also slightly underrepresent blacks and Hispanics while overrepresenting Asians (Berinsky et al. 2012; Chandler, Mueller, and Paolacci 2014). Workers on MTurk also lean towards more liberal attitudes and opinions (Berinsky et al. 2012). There is some evidence that these demographic differences account for minimal differences in effect sizes between MTurk and other Internet survey platforms that claim representative samples (Weinberg et al. 2014). Moreover, careful checks of moderating demographic variables that are not representative of the United States in MTurk samples and/or weighting may alleviate concerns regarding external validity (Mullinix et al. 2016; Weinberg et al. 2014).

Second, concerns regarding internal validity may be exaggerated. Research suggests that data from MTurk are more reliable than undergraduate lab samples and, at minimum, equal to other Internet samples (Behrend et al. 2011; Buhrmester et al. 2011; Paolacci et al. 2010; Weinberg et al. 2014). A number of studies use "catch trials" and/or longitudinal samples to verify respondent demographics and attention to the tasks at hand (Mason and Suri 2012; Rand 2012). Additionally, Peer, Vosgerau, and Acquisti (2014) find that limiting HITs to high-reputation workers (those with $\geq 95$ percent HIT approval ratings) is sufficient to maintain high data quality, and adding catch trials or attention-check questions do not improve data quality further.

\section{Sample and Survey Setup}

Requesters on MTurk can list requirements of workers and block anyone not meeting those requirements from accessing the HIT. I created a sampling frame within MTurk by limiting workers to only those with a U.S. address and, following the findings of Berinsky et al. (2012), further restricted the sample to only those workers with a HIT approval rate $\geq 95$ percent to improve data quality.

I published a batch of 150 to 200 HITs approximately every week during the 12-month period. After each assignment closed, I flagged previous participants so they could neither repeat nor see new batches of the survey. Additionally, I frequently checked the major MTurk message boards to be sure that no major discussions were taking place online that disclosed the nature of the experimental manipulation. I chose to open small batches of the survey experiment at multiple intervals rather than post a single large batch with thousands of assignments so that 
the experiment was always relatively fresh to anyone who had not yet completed the survey. Respondents who accepted the HIT were taken to a redirect page written in JavaScript that randomized the survey condition by randomly sending the respondent to one of 50 different survey webpages to complete the survey. The first treatment assignment phase directed respondents to one of 10 sets of first names (each set contained 20 different first names), with the goal of 10 percent to each. The second treatment assignment phase directed respondents to either first names only or one of four last name sets, with the goal of 30 percent to first names only and 17.5 percent to each of the last name conditions (within each assignment from phase 1). In total, 8,424 respondents started the survey and 7,881 completed the survey (93.5 percent).

\section{Selecting Names to Test}

I selected names for this study using New York state birth record data for all births from 1994 to 2012 obtained from the New York State Department of Health to examine population-level race and SES characteristics. ${ }^{4}$ These data separately list the total number of births by (1) name and mother's race and (2) name and mother's education. This data structure allowed me, for example, to choose two names similar in terms of mother's race but different in terms of mother's education-in other words, a black lower-SES name and a black middle- to upper-SES name. Two examples used in this study are DaQuan and Jabari; 91.8 percent of children named DaQuan and 92.1 percent of children named Jabari are born to black mothers. These names are equal in blackness but vary by mother's education; only 12.8 percent of mothers who name their child DaQuan have some college or more education, whereas 56.8 percent of mothers who name their child Jabari have some college or more education.

Additionally, when possible, I selected names that were used in previous or ongoing audit studies from different disciplines (e.g., Bertrand and Mullainathan 2004; Gaddis 2015; Milkman et al. 2012). This will permit me, in future work, to compare how different racial response rates by individual names in those studies match with the racial perception rates of this study. In total, I use 200 first names; 10 different sets of 20 names, 80 of which are black ( $>50$ percent born to black mothers in the New York data), 80 of which are white ( $>50$ percent born to white mothers in the New York data), and 40 of which are Hispanic. ${ }^{5}$ Within each set of 20 first names, 8 are black, 8 are white, and 4 are Hispanic. For brevity and because fewer correspondence audits to date have examined outcomes using Hispanic names, I do not include any additional results for Hispanic first names in this article (see Gaddis 2017). Table 1 shows the full list of names in each set, and Table A1 in the online supplement shows the full list of names by mother's race, mother's education, and total frequency in the New York state birth record data.

Finally, I chose last names using frequently occurring surnames from the 2000 Census, which lists the population racial composition of last names in the United States (U.S. Census Bureau 2012). I show the population-level racial occurrence of these last names in Table 2. 


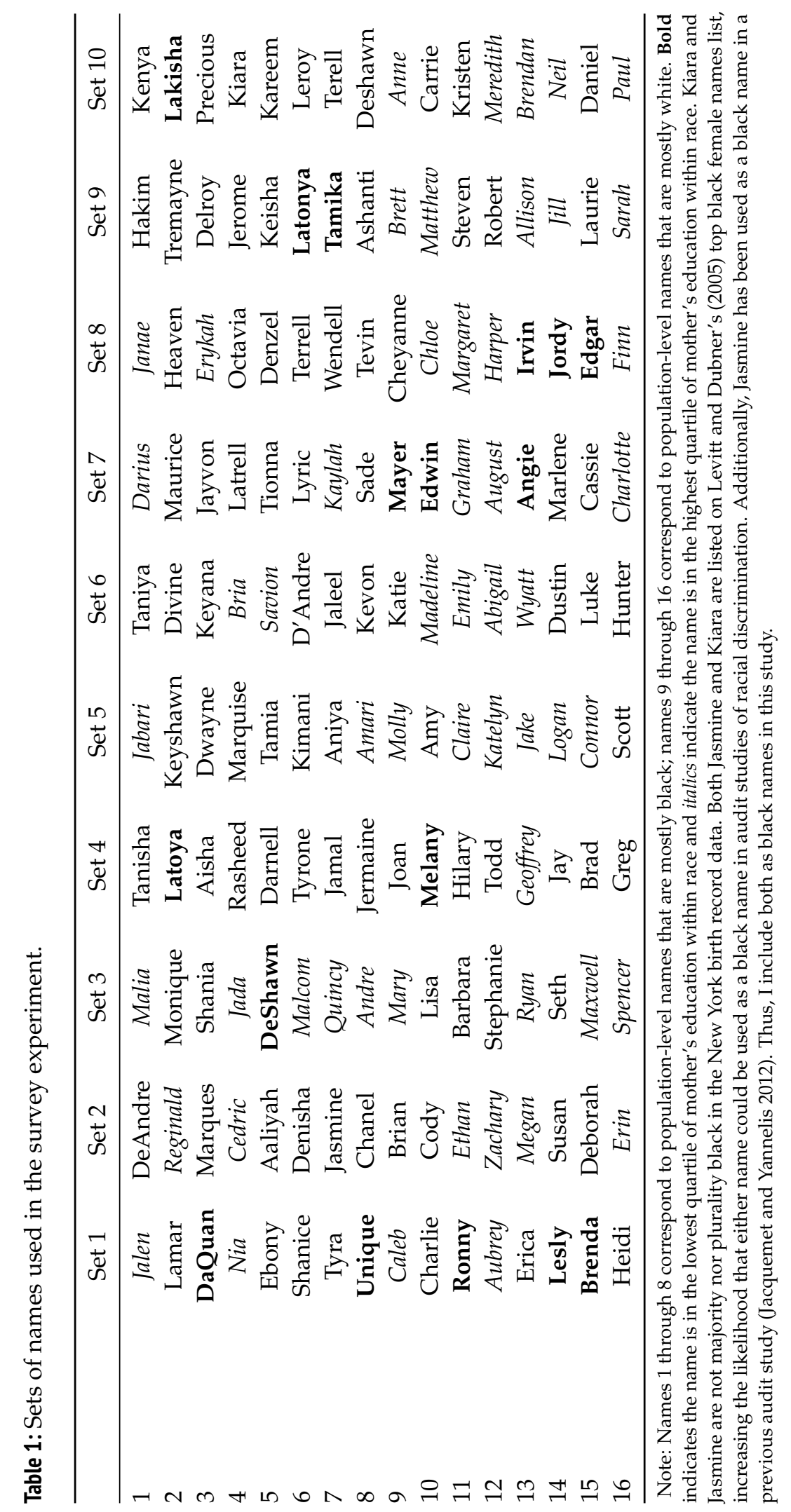


Table 2: Last names used in the survey experiment.

\begin{tabular}{lcccc}
\hline Name & Rank & Percent White & Percent Black & Percent Hispanic \\
\hline Washington & 138 & $5.2 \%$ & $89.9 \%$ & $1.5 \%$ \\
Jefferson & 594 & $18.7 \%$ & $75.2 \%$ & $1.6 \%$ \\
Booker & 902 & $30.0 \%$ & $65.6 \%$ & $1.5 \%$ \\
Banks & 278 & $41.3 \%$ & $54.2 \%$ & $1.5 \%$ \\
Jackson & 18 & $41.9 \%$ & $53.0 \%$ & $1.5 \%$ \\
Mosley & 699 & $42.7 \%$ & $52.8 \%$ & $1.5 \%$ \\
Becker & 315 & $96.4 \%$ & $0.5 \%$ & $1.4 \%$ \\
Meyer & 163 & $96.1 \%$ & $0.5 \%$ & $1.6 \%$ \\
Walsh & 265 & $95.9 \%$ & $1.0 \%$ & $1.4 \%$ \\
Larsen & 572 & $95.6 \%$ & $0.4 \%$ & $1.5 \%$ \\
Nielsen & 765 & $95.6 \%$ & $0.3 \%$ & $1.7 \%$ \\
McGrath & 943 & $95.9 \%$ & $0.6 \%$ & $1.6 \%$ \\
Stein & 720 & $95.6 \%$ & $0.9 \%$ & $1.6 \%$ \\
Decker & 555 & $95.4 \%$ & $0.8 \%$ & $1.7 \%$ \\
Andersen & 954 & $95.5 \%$ & $0.6 \%$ & $1.7 \%$ \\
Hartman & 470 & $95.4 \%$ & $1.5 \%$ & $1.2 \%$ \\
Orozco & 690 & $3.9 \%$ & $0.1 \%$ & $95.1 \%$ \\
Velazquez & 789 & $4.0 \%$ & $0.5 \%$ & $94.9 \%$ \\
Gonzalez & 23 & $4.8 \%$ & $0.4 \%$ & $94.0 \%$ \\
Hernandez & 15 & $4.6 \%$ & $0.4 \%$ & $93.8 \%$ \\
\hline
\end{tabular}

Note: Data from U.S. Census Bureau (2012).

\section{Survey Questions}

The pertinent survey question on racial perception asked: "For each of the following names, list the race or ethnicity that you associate with that name (for example: white, black, Hispanic, Latino, Asian, etc.). ${ }^{6}$ If you do not have a clear racial or ethnic association with a name, you may type "none'." Open-ended responses were recoded to indicate Asian (1.7 percent of all responses), black (40.7 percent), Hispanic or Latino (8.4 percent), white (44.2 percent), none (4.8 percent), or other (0.2 percent). When multiple racial and/or ethnic categories were suggested by the respondent, I used the first word typed as the primary perception; only 0.3 percent of all answers indicated some form of bi- or multiracial perception. ${ }^{7}$

In addition to the questions on racial perceptions from names, the first page of the survey included nine demographic and background questions about the survey respondent: age, race and/or ethnicity, sex, relationship status, any children less than 18, highest level of education completed, combined household income, employment status, and zip code. The second page included the name questions, and the final page of the survey asked for the respondent's MTurk ID for verification and payment. 


\section{Methods of Analysis}

In the first part of the next section, I present basic bivariate descriptive results that show the perception of names as either "congruent" or "incongruent" with population-level naming practices and prior correspondence audits. This approximates the real-world process that occurs during field experiments. For example, a respondent's recoded response of perception as "black" is congruent with a name used to signal a black applicant in previous correspondence audits, but a recoded response of perception as "none," "Asian," or "white" is incongruent with the same name. The match between a hypothetical researcher's intended signal of race and a respondent's perceived racial identification of that person is what matters in a field experiment. For simplification, I refer to a matched perception with the intended signal as "congruent perception" at the individual level and "congruent perception rate" at the aggregate level in the remainder of this article.

In the second part of the next section, I use logistic regression to model the effects of name characteristics and respondent characteristics in predicting odds ratios of congruent perceptions of names:

$$
\ln (p /[1-p])=\alpha_{n}+\beta_{1} X_{n}+\beta_{2} V_{r}
$$

In the equation above, $\alpha_{n}$ is the name-level intercept, $X_{n}$ represents a vector of name variables (gender, last name, mother's education quartile, mother's race percentage, and total frequency), and $V_{r}$ represents a vector of respondent variables (age, race and/or ethnicity, sex, relationship status, any children less than 18, highest level of education completed, combined household income, and employment status). Mother's race percentage (black or white) is a continuous variable, whereas mother's education is transformed into race-specific quartiles of the percentage of mothers with some college or more education. These models include cluster-corrected standard errors at the respondent level.

\section{Results}

\section{Descriptive Results}

The first two figures show the congruent perception rates of all individual black (Figure 1) and white (Figure 2) names by type of last name (white last name included, black last name included, and no last name). Each bar indicates the percentage of survey respondents whose perception of a name matches the signal. Names are sorted in ascending order by racially matched last name perception rates. The primary discussion in this section focuses on congruent perception rates when names are matched with the appropriate race last name. Generally, the congruent perception rates are lower when first names are given no last name or a racially mismatched last name. Detailed discussion of these aspects follows in the regression results section.

There is much variation in congruent perception rates within each set of racialized names. For black names (Figure 1), the respondents were least likely to congruently perceive the names Bria, Sade, Kaylah, Lyric, and Jasmine ${ }^{8}$ when matched 


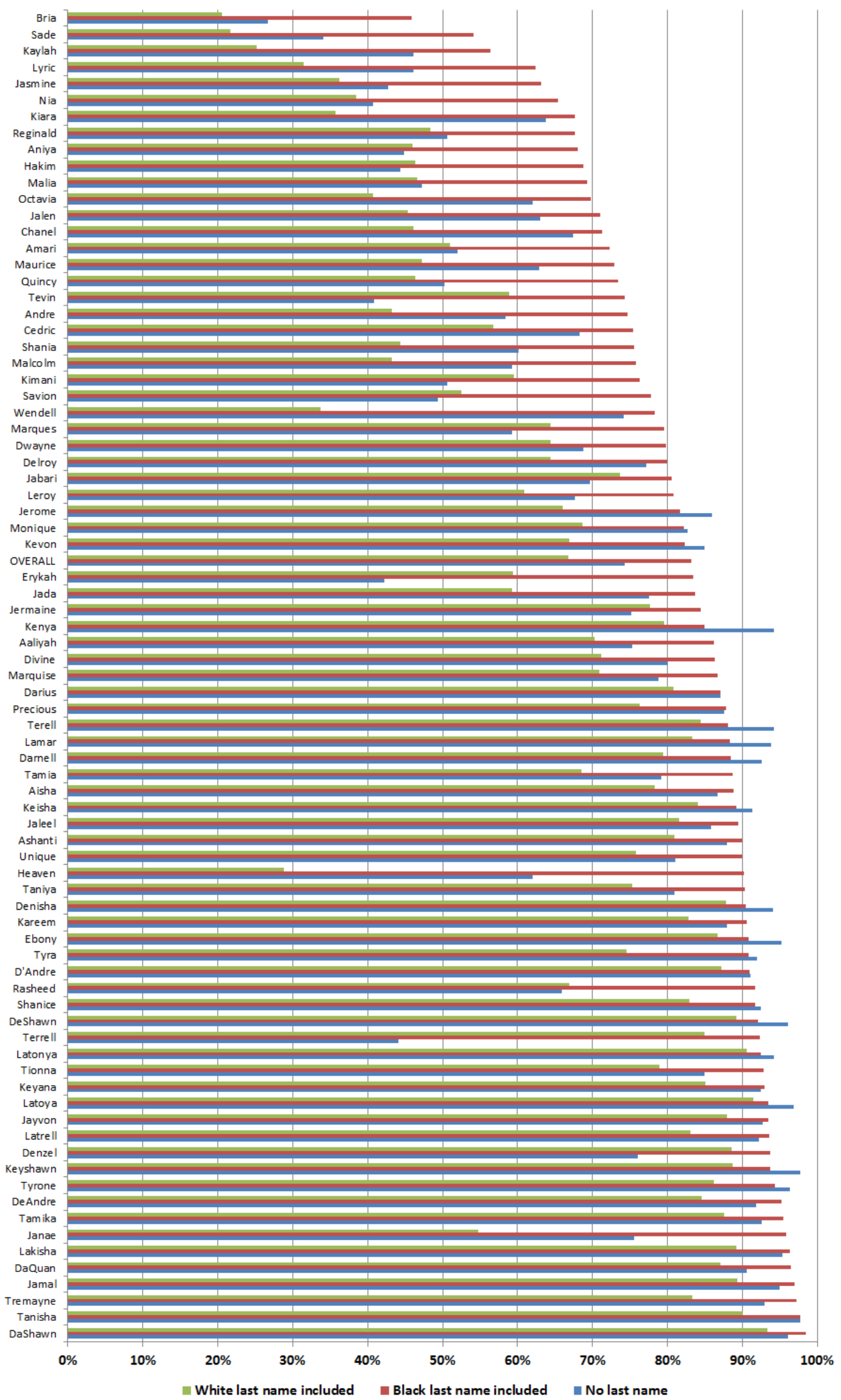

Figure 1: Congruent perception rates of black first names by last name status. 


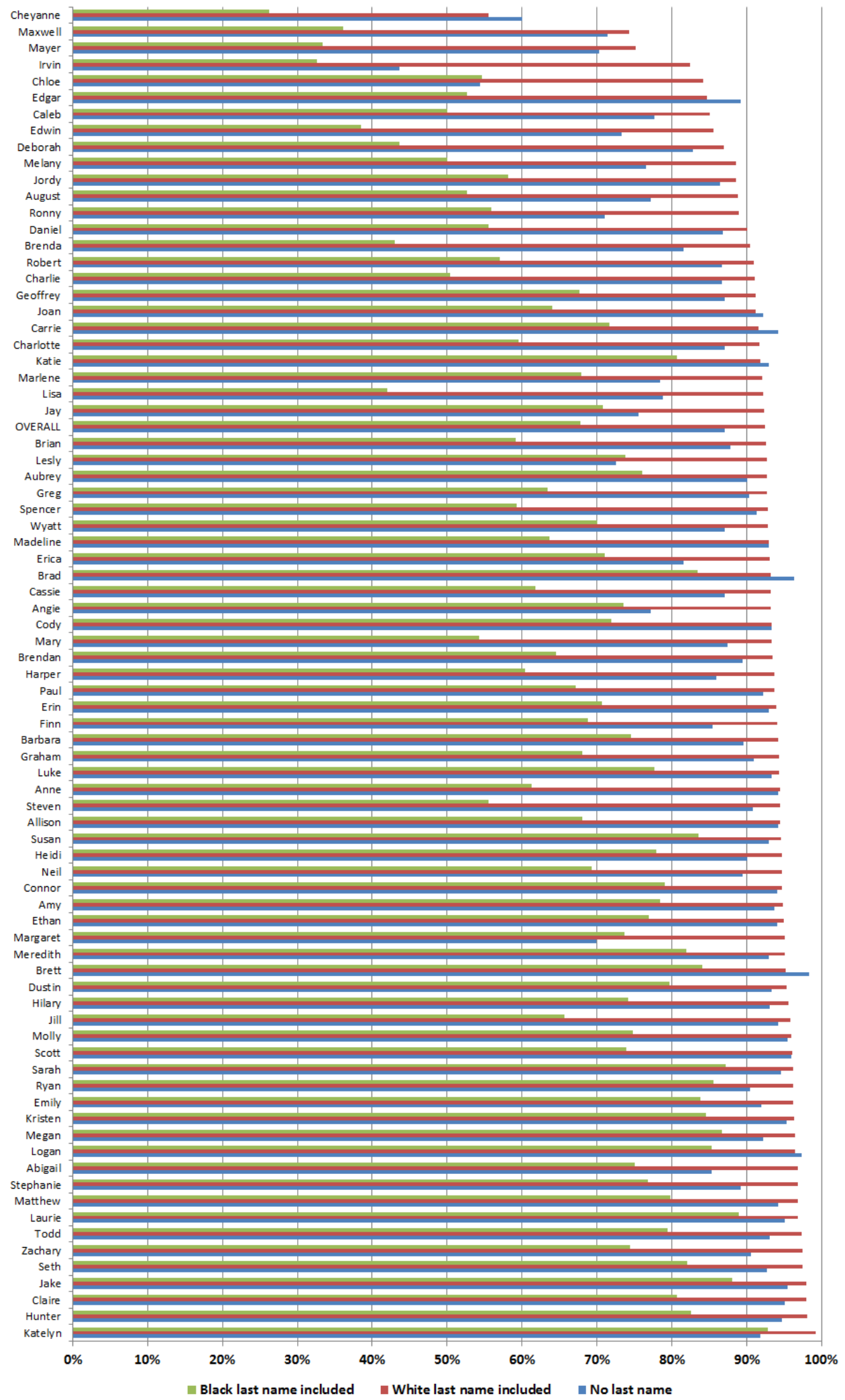

Figure 2: Congruent perception rates of white first names by last name status. 
with a black last name. All of these names were perceived as black among less than 65 percent of the respondents. Even when black last names were included, 20 of the 80 black names ( 25 percent) were perceived as black among less than 75 percent of the respondents, indicating poor choices for use in experiments signaling race. Conversely, congruent perception rates were quite high for the names DaShawn, Tanisha, Tremayne, Jamal, and Daquan. All of these names were perceived as black among more than 95 percent of the respondents. When black last names were included, 30 of the 80 black names ( 37.5 percent) were perceived as black among more than 90 percent of the respondents, indicating very good choices for use in field experiments signaling race. The congruent perception rate across all black names is 75.0 percent when given no last name, 82.5 percent when given a black last name, and 66.5 percent when given a white last name.

For white names (Figure 2), the respondents were least likely to congruently perceive the names Cheyanne, Maxwell, Mayer, Irvin, and Chloe when matched with a white last name. All of these names were perceived as white among less than 85 percent of the respondents. Only Cheyanne (55.6 percent) and Maxwell (74.3 percent) were perceived as white among less than 75 percent of the respondents, indicating poor choices for use in field experiments signaling race. Conversely, congruent perception rates were extremely high for the names Katelyn, Hunter, Claire, Jake, and Seth. All of these names were perceived as white among more than 97 percent of the respondents. When white last names were included, 67 of the 80 white names (83.8 percent) were perceived as white among more than 90 percent of the respondents, indicating very good choices for use in experiments signaling race. The respondent congruent perception rate for all white names is 87.3 percent when given no last name, 92.4 percent when given a white last name, 67.9 percent when given a black last name, and 17.8 percent when given a Hispanic last name.

One other significant variation that stands out from these figures comes from differences by mothers' education. Respondents are much more likely to congruently perceive a black name from mothers with lower education levels like DaShawn, DaQuan, or Lakisha rather than from mothers with higher education levels like Nia, Malcolm, or Malia. Respondents are also much more likely to congruently perceive a white name from mothers with higher education levels like Claire, Jake, or Abigail rather than from mothers with lower education like Cheyanne, Irvin, or Jordy, although the patterns for white names do not appear as strong as for black names.

Table 3 delves into the raw data and confirms the patterns discussed above. Generally, respondents congruently perceive white names at higher rates than others except when matched with a Hispanic last name. Respondents also congruently perceive male and female white names at equal rates but have less trouble congruently perceiving male rather than female black names. Finally, there's some evidence that black and white respondents can congruently perceive names that match their own race more readily that those of other races. 
Table 3: Descriptive statistics: congruent perception.

\begin{tabular}{lcc}
\hline & \multicolumn{2}{c}{ Signaled Race of Name } \\
& White & Black \\
\hline Overall congruent perception & $73.4 \%$ & $74.7 \%$ \\
Characteristics of name & & \\
With no last name & & \\
With racially matched last name & $87.3 \%$ & $75.0 \%$ \\
With white last name (black first only) & $92.4 \%$ & $82.5 \%$ \\
With black last name (white first only) & - & $66.5 \%$ \\
With Hispanic last name (white first only) & $67.9 \%$ & - \\
Male & $17.8 \%$ & - \\
Female & $73.0 \%$ & $77.3 \%$ \\
Lowest quartile of mother's education & $73.7 \%$ & $71.9 \%$ \\
Middle two quartiles of mother's education & $64.0 \%$ & $91.8 \%$ \\
Highest quartile of mother's education & $73.2 \%$ & $76.8 \%$ \\
Characteristics of respondent & $75.7 \%$ & $59.5 \%$ \\
White & & \\
Black & & \\
Hispanic & & $74.7 \%$ \\
Asian & $67.7 \%$ & $79.6 \%$ \\
Male & $69.8 \%$ & $75.4 \%$ \\
Female & $69.1 \%$ & $67.7 \%$ \\
Total $N$ & $73.1 \%$ & $75.0 \%$ \\
Respondent $N$ & $73.6 \%$ & $74.3 \%$ \\
\hline
\end{tabular}

Note: Each respondent was asked to identify 16 different white and black names (see Table 1).

\section{Regression Analyses}

Table 4 shows logistic regression analyses predicting congruent perception of a black first name for 63,048 cases (7,881 respondents $x 8$ black names per respondent). The first model only controls for name characteristics and the second model also includes respondent characteristics. Model 1 shows that respondents are more likely to congruently perceive black names that are in the lowest quartile of mother's education (odds ratio $[\mathrm{OR}]=2.84$ ), when a black last name is included $(\mathrm{OR}=1.63)$, and when a name is more black among the New York population of mothers (OR = 3.73). Respondents are less likely to congruently perceive black names when the name is female ( $\mathrm{OR}=0.72)$, when a white last name is included ( $\mathrm{OR}=0.65)$, when the name is in the highest quartile of mother's education $(\mathrm{OR}=0.43)$, and when a name is more popular in the aggregate New York birth population $(\mathrm{OR}=0.96)$. In the second model, we see that the respondent's own characteristics matter. None of the odds ratios for the name characteristics change substantially, but the results suggest that black respondents are more likely to congruently perceive black names 
$(\mathrm{OR}=1.43)$, as well as individuals in the middle age categories (age 25 to 34 : $\mathrm{OR}=$ 1.30; age 35 to 49 : $\mathrm{OR}=1.32$ ) and individuals with a household income of $\$ 25,000$ to $\$ 49,999$ ( $\mathrm{OR}=1.09)$ or $\$ 75,000$ and higher $(\mathrm{OR}=1.20)$.

Table 5 shows logistic regression analyses predicting congruent perception of a white first name for 63,048 cases. Both models control for various characteristics of the name itself, and the second model includes controls for the individual respondent's characteristics. Model 1 shows that respondents are more likely to congruently perceive white names when a name is female $(\mathrm{OR}=1.08)$, when a white last name is included ( $\mathrm{OR}=1.80)$, when a name is in the highest quartile of mother's education ( $\mathrm{OR}=1.10)$, when a name is more white among the New York population of mothers $(\mathrm{OR}=2.18)$, and when a name is more popular in the aggregate New York birth population $(\mathrm{OR}=1.04)$. Respondents are less likely to congruently perceive white names when a black last name is included (OR $=0.30)$, when a Hispanic last name is included $(\mathrm{OR}=0.03)$, and when a name is in the lowest quartile of mother's education $(\mathrm{OR}=0.50)$. In the second model, we see that the respondent's own characteristics matter somewhat. None of the odds ratios for the name characteristics change substantially, but the results suggest that blacks $(\mathrm{OR}=0.62)$, Hispanics $(\mathrm{OR}=0.77)$, and individuals with a bachelor's degree or greater $(\mathrm{OR}=0.83)$ are less likely to congruently perceive a white name.

\section{Robustness Analyses}

One alternative strategy is to model the dependent variable as whether or not the respondent simply perceives a name as black or white instead of whether the respondent congruently perceives a name as black or white. This strategy does not completely mimic the correspondence audit process of sending and receiving a signal because the choice of what signal sent is omitted. In these models I run regressions similar to model 2 presented in Table 4 and Table 5 separately for the sets of 80 black names and 80 white names. The results are very similar to those presented above (see Table A2 in the online supplement). Of note, the models suggest that the "more black" a white name is (based on the percentage of black mothers in the New York data naming their child that name), the more likely a respondent is to perceive that name as black; conversely, the "more white" a black name is (based on the percentage of white mothers in the New York data naming their child that name), the more likely a respondent is to perceive that name as white.

\section{Discussion and Conclusion}

In the 1964 Supreme Court case Jacobellis v. Ohio, Justice Potter Stewart famously said "I know it when I see it" in reference to what constitutes pornography. Many scholars seemingly have taken the same tactic when deciding what constitutes a black name: they know it when they see (or hear) it. The underlying assumption that black names comprise a uniform body that signals the same information has dominated the leading method used to investigate racial discrimination since the early 2000s. However, the present research shows that this assumption fails to hold 
Table 4: Logistic regressions predicting congruent perception of a black first name.

\begin{tabular}{|c|c|c|}
\hline & (1) & $(2)$ \\
\hline \multicolumn{3}{|l|}{ Name Characteristics } \\
\hline Female name & $\begin{array}{c}0.724^{\dagger} \\
(0.015)\end{array}$ & $\begin{array}{c}0.724^{\dagger} \\
(0.015)\end{array}$ \\
\hline \multicolumn{3}{|l|}{ Last name (reference: no last name) } \\
\hline Black last name included & $\begin{array}{c}1.632^{\dagger} \\
(0.054)\end{array}$ & $\begin{array}{c}1.639^{\dagger} \\
(0.054)\end{array}$ \\
\hline White last name included & $\begin{array}{c}0.653^{\dagger} \\
(0.020)\end{array}$ & $\begin{array}{c}0.651^{\dagger} \\
(0.020)\end{array}$ \\
\hline \multicolumn{3}{|c|}{ Quartile of mother's education (reference: middle two quartiles) } \\
\hline Lowest quartile of mother's education & $\begin{array}{c}2.839^{\dagger} \\
(0.159)\end{array}$ & $\begin{array}{c}2.852^{\dagger} \\
(0.160)\end{array}$ \\
\hline Highest quartile of mother's education & $\begin{array}{r}0.433^{\dagger} \\
(0.010)\end{array}$ & $\begin{array}{r}0.430^{\dagger} \\
(0.010)\end{array}$ \\
\hline Percent black mothers in New York data & $\begin{array}{c}3.728^{+} \\
(0.370)\end{array}$ & $\begin{array}{c}3.915^{+} \\
(0.387)\end{array}$ \\
\hline Total number of births in New York data (ln) & $\begin{array}{c}0.960^{\dagger} \\
(0.012)\end{array}$ & $\begin{array}{c}0.960^{\dagger} \\
(0.012)\end{array}$ \\
\hline \multicolumn{3}{|l|}{ Respondent Characteristics } \\
\hline Black (reference: white) & & $\begin{array}{c}1.429^{\dagger} \\
(0.080)\end{array}$ \\
\hline Hispanic & & $\begin{array}{c}1.096 \\
(0.062)\end{array}$ \\
\hline Female & & $\begin{array}{c}0.976 \\
(0.028)\end{array}$ \\
\hline Age: 25-34 (reference: 18-24) & & $\begin{array}{r}1.295^{\dagger} \\
(0.050)\end{array}$ \\
\hline Age: $35-49$ & & $\begin{array}{c}1.316^{\dagger} \\
(0.060)\end{array}$ \\
\hline Age: $50+$ & & $\begin{array}{c}1.006 \\
(0.056)\end{array}$ \\
\hline Education: some college (reference: $\leq \mathrm{HS}$ ) & & $\begin{array}{c}1.058 \\
(0.051)\end{array}$ \\
\hline Education: Associate's degree or other 2-year degree & & $\begin{array}{c}1.043 \\
(0.061)\end{array}$ \\
\hline Education: Bachelor's degree or higher & & $\begin{array}{c}1.096 \\
(0.053)\end{array}$ \\
\hline Income: $\$ 25,000-\$ 49,999$ (reference: $<\$ 25,000$ ) & & $\begin{array}{c}1.089 * \\
(0.043)\end{array}$ \\
\hline Income: $\$ 50,000-\$ 74,999$ & & $\begin{array}{c}1.074 \\
(0.048)\end{array}$ \\
\hline Income: $\$ 75,000+$ & & $\begin{array}{c}1.197^{\dagger} \\
(0.054)\end{array}$ \\
\hline Constant & $\begin{array}{c}1.980^{\dagger} \\
(0.264)\end{array}$ & $\begin{array}{c}1.363^{*} \\
(0.200)\end{array}$ \\
\hline$N$ & 63,048 & 63,048 \\
\hline
\end{tabular}

Note: Odds ratios shown. Regressions also control for respondent's marital status, employment status, and whether respondent has any children under the age of 18 . Cluster-corrected (respondent level) standard errors. ${ }^{+} p<0.01,{ }^{*} p<0.05$. 
Table 5: Logistic regressions predicting congruent perception of a white first name.

\begin{tabular}{|c|c|c|}
\hline & (1) & (2) \\
\hline \multicolumn{3}{|l|}{ Name Characteristics } \\
\hline Female name & $\begin{array}{c}1.079^{\dagger} \\
(0.025)\end{array}$ & $\begin{array}{r}1.079^{\dagger} \\
(0.025)\end{array}$ \\
\hline \multicolumn{3}{|l|}{ Last name (reference: no last name) } \\
\hline White last name included & $\begin{array}{c}1.795^{\dagger} \\
(0.089)\end{array}$ & $\begin{array}{r}1.812^{\dagger} \\
(0.090)\end{array}$ \\
\hline Black last name included & $\begin{array}{c}0.302^{\dagger} \\
(0.013)\end{array}$ & $\begin{array}{r}0.301^{\dagger} \\
(0.013)\end{array}$ \\
\hline Hispanic last name included & $\begin{array}{c}0.030^{\dagger} \\
(0.001)\end{array}$ & $\begin{array}{r}0.029^{\dagger} \\
(0.001)\end{array}$ \\
\hline \multicolumn{3}{|c|}{ Quartile of mother's education (reference: middle two quartiles) } \\
\hline Lowest quartile of mother's education & $\begin{array}{c}0.502^{\dagger} \\
(0.019)\end{array}$ & $\begin{array}{r}0.502^{\dagger} \\
(0.019)\end{array}$ \\
\hline Highest quartile of mother's education & $\begin{array}{c}1.098^{\dagger} \\
(0.030)\end{array}$ & $\begin{array}{r}1.096^{\dagger} \\
(0.030)\end{array}$ \\
\hline Percent white mothers in New York data & $\begin{array}{c}2.183^{\dagger} \\
(0.280)\end{array}$ & $\begin{array}{r}2.238^{\dagger} \\
(0.288)\end{array}$ \\
\hline Total number of births in New York data (ln) & $\begin{array}{c}1.044^{\dagger} \\
(0.011)\end{array}$ & $\begin{array}{r}1.043^{\dagger} \\
(0.011)\end{array}$ \\
\hline \multicolumn{3}{|l|}{ Respondent Characteristics } \\
\hline Black (reference: white) & & $\begin{array}{r}0.620^{\dagger} \\
(0.035)\end{array}$ \\
\hline Hispanic & & $\begin{array}{r}0.773^{\dagger} \\
(0.043)\end{array}$ \\
\hline Female & & $\begin{array}{c}1.020 \\
(0.035)\end{array}$ \\
\hline Age: 25-34 (reference: 18-24) & & $\begin{array}{c}0.991 \\
(0.046)\end{array}$ \\
\hline Age: $35-49$ & & $\begin{array}{c}1.021 \\
(0.057)\end{array}$ \\
\hline Age: $50+$ & & $\begin{array}{c}1.121 \\
(0.080)\end{array}$ \\
\hline Education: some college (reference: $\leq \mathrm{HS}$ ) & & $\begin{array}{c}0.905 \\
(0.056)\end{array}$ \\
\hline Education: Associate's degree or other 2-year degree & & $\begin{array}{c}0.935 \\
(0.068)\end{array}$ \\
\hline Education: Bachelor's degree or higher & & $\begin{array}{r}0.832^{\dagger} \\
(0.050)\end{array}$ \\
\hline Income: $\$ 25,000-\$ 49,999$ (reference: $<\$ 25,000$ ) & & $\begin{array}{c}0.959 \\
(0.047)\end{array}$ \\
\hline Income: $\$ 50,000-\$ 74,999$ & & $\begin{array}{c}0.903 \\
(0.049)\end{array}$ \\
\hline Income: $\$ 75,000+$ & & $\begin{array}{c}0.967 \\
(0.053)\end{array}$ \\
\hline Constant & $\begin{array}{r}2.681^{\dagger} \\
(0.354)\end{array}$ & $\begin{array}{r}3.076^{\dagger} \\
(0.473)\end{array}$ \\
\hline$N$ & 63,048 & 63,048 \\
\hline
\end{tabular}

Note: Odds ratios shown. Regressions also control for respondent's marital status, employment status, and whether respondent has any children under the age of 18. Cluster-corrected (respondent level) standard errors. ${ }^{\dagger} p<0.01,{ }^{*} p<0.05$ 
up when put under the scientific microscope. Indeed, black names used in previous correspondence audits vary significantly by individual perceptions of race. I find that a number of characteristics of an individual name matter: gender, popularity, type of last name included, and the average level of education of mothers who commonly give that name, among others.

The immediate implications of these findings are obvious: researchers can use this information to select names that signal race more clearly in correspondence audits. Whether researchers select the best-performing names among those I tested or conduct their own pretests before embarking on future correspondence audits, internal validity should increase in future racial discrimination research.

However, we should also question what these results might mean for the current body of discrimination research that is mostly not based on scientific selection of names to signal race. Differences in racial perceptions from names might explain differences in outcomes within and between correspondence audits. A recent trio of correspondence audits highlights this possibility (Darolia et al. 2016; Deming et al. 2016; Gaddis 2016). Three sets of researchers separately examined the effects of for-profit versus not-for-profit educational credentials in the labor market for black and white job candidates. Despite conducting the three correspondence audits during similar time periods with similar research questions and across many of the same cities, the findings regarding racial discrimination were quite different. Each chose different names to signal race, with one going the unique route of using generic or "white" first names coupled with "black" last names to signal a black applicant and found no evidence of racial discrimination (Darolia et al. 2016). Although other differences between these studies exist, the possibility that the racial signal from names might influence correspondence audit outcomes warrants further investigation.

\section{Notes}

1 This search, performed in September 2016, examined citation networks from high-profile audit studies, searches through the National Bureau of Economic Research and the Social Science Research Network, and personal correspondence between the author and a number of researchers conducting these studies.

2 A database of this research will be available in the near future at http:/ / www.auditstudies.com.

3 Bertrand and Mullainathan (2004) found that some distinctively black names, Maurice and Jerome in particular, were not perceived as strongly black in a small test sample in Chicago.

4 The choice of New York birth record data is one of convenience. To my knowledge, no national-level data are available. The only other available large-scale, multiyear birth record data come from California. These data are expensive to obtain. Additionally, the racial demographics of New York are closer than California to the national percentages (e.g., blacks are 13.2 percent of the population nationally, 15.9 percent of the population in New York, and only 6.5 percent of the population in California). 1994 through 2012 was the full set of years available from New York at the beginning of this project. Although racial and SES-based naming practices may vary somewhat across regions, the question of importance is whether racial perceptions from names vary across regions. In supplemental analyses, I test whether respondents from New York vary from respondents in 
the rest of the United States. I find no substantive differences in these analyses (available from author upon request), suggesting that the use of New York data likely has no significant bearing on the results.

5 I treat two names as black even though the New York data show that a plurality of mothers are white who name their children these two names: Jasmine and Kiara. In the case of Jasmine, one previous correspondence audit used the name to signal a black person (Jacquemet and Yannelis 2012). Additionally, both Jasmine and Kiara are listed on Levitt and Dubner's (2005) top black female names list, increasing the likelihood that either name could be used as a black name in audit studies of racial discrimination.

6 The survey question asks about "race or ethnicity." For brevity, I refer to this simply as race, even when discussing Hispanic ethnicity.

7 Dropping multiracial responses or treating them as "other" does not affect the substantive findings.

8 The low congruent perception rate of Jasmine is expected because only 33 percent of Jasmines in New York are born to black mothers. Again, because a previous correspondence audit used the name to signal a black person (Jacquemet and Yannelis 2012), I treat the name as black in this study.

\section{References}

Behrend, Tara S., David J. Sharek, Adam W. Meade, and Eric N. Wiebe. 2011. “The Viability of Crowdsourcing for Survey Research." Behavior Research Methods 43(3):800-13. https : //doi.org/10.3758/s13428-011-0081-0

Berinsky, Adam J., Gregory A. Huber, and Gabriel S. Lenz. 2012. “Evaluating Online Labor Markets for Experimental Research: Amazon.com's Mechanical Turk." Political Analysis 20(3):351-68. https : //doi .org/10.1093/pan/mpr057

Bertrand, Marianne, and Sendhil Mullainathan. 2004. "Are Emily and Greg More Employable than Lakisha and Jamal? A Field Experiment on Labor Market Discrimination." The American Economic Review 94(4):991-1013. https : / doi .org/10.1257/0002828042002561

Buhrmester, Michael, Tracy Kwang, and Samuel D. Gosling. 2011. “Amazon's Mechanical Turk: A New Source of Inexpensive, Yet High-Quality, Data?" Perspectives on Psychological Science 6(1):3-5. https ://doi .org/10.1177/1745691610393980

Butler, Daniel M., and David E. Broockman. 2011. “Do Politicians Racially Discriminate Against Constituents? A Field Experiment on State Legislators." American Journal of Political Science 55(3):463-77. https://doi .org/10.1111/j.1540-5907.2011.00515.x

Campbell, Colin S., and S. Michael Gaddis. Forthcoming. “II Don't Agree with Giving Cash': A Survey Experiment Examining Support for Public Assistance." Social Science Quarterly. http://onlinelibrary.wiley.com/doi/10.1111/ssqu.12338/abstract

Chandler, Jesse, Pam Mueller, and Gabriele Paolacci. 2014. "Nonnaiveté among Amazon Mechanical Turk Workers: Consequences and Solutions for Behavioral Researchers." Behavior Research Methods 46(1):112-30. https : //doi .org/10.3758/s13428-013-0365-7

Darolia, Rajeev, Cory Koedel, Paco Martorell, Katie Wilson, and Francisco Perez-Arce. 2016. "Race and Gender Effects on Employer Interest in Job Applicants: New Evidence from a Resume Field Experiment." Applied Economics Letters 23(12):853-6. https : //doi . org/10. $1080 / 13504851.2015 .1114571$

Deming, David J., Noam Yuchtman, Amira Abulafi, Claudia Goldin, and Lawrence F. Katz. 2016. "The Value of Postsecondary Credentials in the Labor Market: An Experimental 
Study." American Economic Review 106(3): 778-806. https://doi.org/10.1257/aer. 20141757

Dowling, Conor, and Michael G. Miller. 2016. “Experimental Evidence on the Relationship Between Interest Group Funding and Candidate Vote Share." Journal of Experimental Political Science 3(2):152-63. https : //doi .org/10.1017/XPS. 2016.5

Einstein, Katherine Levine, and David M. Glick. 2017. "Does Race Affect Access to Government Services? An Experiment Exploring Street-Level Bureaucrats and Access to Public Housing." American Journal of Political Science 61(1):100-16. https: //doi.org/10.1111/ajps.12252

Figlio, David N. 2005. "Names, Expectations and the Black-White Test Score Gap." NBER Working Paper No. 11195.

Fryer, Roland G., and Steven D. Levitt. 2004. "The Causes and Consequences of Distinctively Black Names." Quarterly Journal of Economics 119(3):767-805. https : //doi .org/10.1162/ 0033553041502180

Gaddis, S. Michael. 2015. “Discrimination in the Credential Society: An Audit Study of Race and College Selectivity in the Labor Market." Social Forces 93(4):1451-79. https: //doi.org/10.1093/sf/sou111

Gaddis, S. Michael. 2016. "A Field Experiment on Associate Degrees and Certificates: Statistical Discrimination, Stigma, Signal Boost, and Signal Saturation." Working paper.

Gaddis, S. Michael. 2017. "Racial/Ethnic Perceptions from Hispanic Names: Selecting Names to Test for Discrimination." Working paper. Retrieved August 8, 2017. https : //ssrn. com/abstract $=2975829$

Gaddis, S. Michael, and Raj Ghoshal. 2017. "A Racial Stratification System for the $21^{\text {st }}$ Century: The Causes and Consequences of Discrimination among Millennials in Two Experiments." Working paper.

Giulietti, Corrado, Mirco Tonin, and Michael Vlassopoulos. 2015. "Racial Discrimination in Local Public Services: A Field Experiment in the US." IZA Discussion Paper 9290 and CESifo Working Paper 5537. Retrieved June 13, 2016. http://ftp.iza.org/dp9290 .pdf

Hanson, Andrew, and Zackary Hawley. 2011. "Do Landlords Discriminate in the Rental Housing Market? Evidence from an Internet Field Experiment in US Cities." Journal of Urban Economics 70(2-3):99-114. https://doi .org/10.1016/j · jue.2011.02.003

Hanson, Andrew, Zackary Hawley, Bo Liu, and Hal Martin. 2016. “Discrimination in Mortgage Lending: Evidence from a Correspondence Experiment." Journal of Urban Economics 92(2):48-65. https://doi .org/10.1016/j.jue.2015.12.004

Heckman, James J. 1998. “Detecting Discrimination.” Journal of Economic Perspectives 12(2):10116. https://doi.org/10.1257/jep.12.2.101

Heckman, James J., and Peter Siegelman. 1993. “The Urban Institute Audit Studies: Their Methods and Findings." Pp. 187-258 in Clear and Convincing Evidence: Measurement of Discrimination in America, edited by Michael Fix and Raymond. J. Stucyk. Lanham, MD: Urban Institute Press.

Hogan, Bernie, and Brent Berry. 2011. "Racial and Ethnic Biases in Rental Housing: An Audit Study of Online Apartment Listings." City and Community 10(4):351-72. https : //doi.org/10.1111/j.1540-6040.2011.01376.x

Horne, Christine, Brice Darras, Elyse Bean, Anurag Srivastava, and Scott Firckel. 2015. "Privacy, Technology, and Norms: The Case of Smart Meters." Social Science Research 51:64-76. https://doi.org/10.1016/j.ssresearch.2014.12.003 
Horton, John J., David G. Rand, and Richard J. Zeckhauser. 2011. “The Online Laboratory: Conducting Experiments in a Real Labor Market." Experimental Economics 14(3): 399-425. https://doi .org/10.1007/s10683-011-9273-9

Ipeirotis, Panagiotis. 2010. “Demographics of Mechanical Turk." NYU Working Paper Series.

Jacquemet, Nicolas, and Constantine Yannelis. 2012. “Indiscriminate Discrimination: A Correspondence Test for Ethnic Homophily in the Chicago Labor Market." Labour Economics 19(6):824-32. https://doi.org/10.1016/j.labeco.2012.08.004

Kirschenman, Joleen, and Kathryn M. Neckerman. 1991. “'We'd Love to Hire Them But...': The Meaning of Race to Employers." Pp. 203-32 in The Urban Underclass, edited by Christopher Jencks and Paul E. Peterson. Washington, D.C.: Brookings.

Levitt, Steven D., and Stephen J. Dubner. 2005. Freakonomics: A Rogue Economist Explores the Hidden Side of Everything. William Morrow.

Lieberson, Stanley. 2000. A Matter of Taste: How Names, Fashions, and Culture Change. New Haven, CT: Yale University Press.

Lieberson, Stanley, and Kelly S. Mikelson. 1995. “Distinctive African American Names: An Experimental, Historical, and Linguistic Analysis of Innovation." American Sociological Review 60(6):928-46. https: //doi.org/10.2307/2096433

Mason, Winter, and Siddharth Suri. 2012. “Conducting Behavioral Research on Amazon's Mechanical Turk." Behavior Research Methods 44(1):1-23. https://doi.org/10.3758/ s13428-011-0124-6

Milkman, Katherine L., Modupe Akinola, and Dolly Chugh. 2012. “Temporal Distance and Discrimination: An Audit Study in Academia." Psychological Science 23(7):710-7. https://doi.org/10.1177/0956797611434539

Mullinix, Kevin, Thomas J. Leeper, James Druckman, and Jeremy Freese. 2016. “The Generalizability of Survey Experiments." Journal of Experimental Political Science 2(2):109-138. https://doi.org/10.1017/XPS.2015.19

Paolacci, Gabriele, Jesse Chandler, and Panagiotis Ipeirotis. 2010. "Running Experiments on Amazon Mechanical Turk." Judgment and Decision Making 5(5):411-9.

Peer, Eyal, Joachim Vosgerau, and Alessandro Acquisti. 2014. "Reputation as a Sufficient Condition for Data Quality on Amazon Mechanical Turk." Behavior Research Methods 46(4):1023-31. https://doi.org/10.3758/s13428-013-0434-y

Rand, David G. 2012. “The Promise of Mechanical Turk: How Online Labor Markets Can Help Theorists Run Behavioral Experiments." Journal of Theoretical Biology 299: 172-9. https://doi.org/10.1016/j.jtbi.2011.03.004

Sears, David O. 1986. "College Sophomores in the Laboratory: Influences of a Narrow Data Base on Social Psychology's View of Human Nature." Journal of Personality and Social Psychology 51(3):515-30. https: //doi .org/10.1037/0022-3514.51.3.515

Sharma, Rajiv, Arnab Mitra, and Miron Stano. 2015. "Insurance, Race/Ethnicity, and Sex in the Search for a New Physician." Economics Letters 137:150-3. https://doi .org/10. 1016/j. econlet. 2015.11.005

U.S. Census Bureau. 2012. “Genealogy Data: Frequently Occurring Surnames from Census 2000, Census Report Data File A: Top 1000 Names." Retrieved October 20, 2013. https: //www. census.gov/topics/population/genealogy/data/2000_surnames.html

Weinberg, Jill, Jeremy Freese, and David McElhattan. 2014. “Comparing Data Characteristics and Results of an Online Factorial Survey between a Population-Based and CrowdsourceRecruited Sample." Sociological Science 1:292-310. https: //doi .org/10.15195/v1 .a19 
Acknowledgements: An earlier version of this article was presented at the 2015 annual meeting of the American Sociological Association in Chicago, IL. Larry D. Schoen provided access to birth record data from New York. Anup Das, Qing Zheng, Betsy Cliff, and Neala Berkowski served as excellent research assistants on this project. I also thank Shawn Bauldry, Colleen Carey, Philip Cohen, Jonathan Daw, René Flores, Devah Pager, Lincoln Quillian, Charles Seguin, and Ashton Verdery for their helpful comments.

S. Michael Gaddis: Department of Sociology, University of California, Los Angeles. E-mail: mgaddis@soc.ucla.edu. 